\title{
Teknolojik Gelişmelerin Habercilik Uygulamaları Üzerine Etkileri: Türkiye'de Drone Haberciliği
}

\author{
The Effects of Technological Developments on Journalism Practices: Drone Journalism in \\ Turkey
}

\section{Emrah BUDAK}

Öz

Gökyüzünden çekilen görüntülerin haber odalarında işlenmesiyle habercilik alanına yeni bir soluk getiren drone'lar, gazetecilik pratiğinde yaygın bir hale gelmektedir. Drone’lar bulunduğu konum nedeniyle geleneksel kameraların yakalayamayacağı birçok görüntüyü kaydedebilme olanağına sahiptir. Dünyada habercilik alanında kendisini kabul ettiren drone'lar Türkiye’de de bir gazetecilik uygulaması olarak yaygınlık kazanmaktadır. Bu çalışmada, drone haberciliğinin Türkiye’deki gelişim süreci incelenerek haber kuruluşlarındaki muhabirler için ifade ettiği anlam ve haber toplamadaki kullanımı araştırılmıștır. Çalışmada ulusal anlamdaki haber ajansları olan Anadolu Ajansı, Demirören Haber Ajansı, İhlas Haber Ajansı'nın habercilikte drone kullanım pratikleri incelenmiştir. Haber kuruluşlarında drone kullanan muhabirlerle yapılandırılmış görüşmeler yapılarak, betimsel analiz yöntemi neticesinde drone haberciliğinin günümüzdeki mevcut durumu ve gelecekte gazetecilikle ilişkisinin ne yönde olacağı ortaya konulmaya çalışılmıştır. Bu bağlamda elde edilen bulgularda drone’un Türkiye'de habercilik alanında günden güne ağırlığını artırdığı, habercilik alanında oldukça olumlu katkılar sağladığı görülmüştür. Olumlu katkılarının yanı sıra drone’un güvenlik ve etik gibi konularda problemler çıkarabileceği ihtimali üzerinde de durulmuştur.

Anahtar Kelimeler: Drone, Drone Haberciliği, Yeni Medya, Yeni İletişim Teknolojileri, İnsansız Hava Araçları

\begin{abstract}
The drones that breathe new life into the field of journalism by processing the images taken from the sky in the news rooms have become more common in journalism practice. Drones have the ability to record many images due to their location that conventional cameras can not capture. The drones which
\end{abstract}

Arş. Gör., Akdeniz Üniversitesi, İletişim Fakültesi, Antalya, Türkiye, bdkemrah78@gmail.com. Orcid ID: 0000-00016896-7558 
has established itself in the field of journalism worldwide, has also become gained prevalence in Turkey as a journalism practice. This study examined the development process of drone journalism in Turkey; what means the drone journalism for the news reporters and the use of drone journalism in news gathering. In this context the usage practice of drone journalism of national news agencies Anadolu Agency, Demirören News Agency and İhlas News Agency has been investigated. A structured interview has been conducted with the reporters using the drone in the news organizations and the relationship between the current situation of drone journalism and the future of journalism has been tried to be explained by the descriptive analysis method. According to the findings obtained from the study, the drone become more effective in Turkey's news institutions and has been shown to provide a very positive contribution to the field of journalism. In addition to the positive contributions, the possibility of drone being able to raise problems in security and ethics is also emphasized.

Keywords: Drone, Drone Journalism, New Media, New Communication Technologies, Unmanned Air Vehicles

\section{Giriş}

İletişim teknolojilerinin gelişmesiyle birlikte medyadaki habercilik anlayışı da değişmeye başlamıştır. Habercilik alanındaki yaşanan değişimlerden biri drone'ların haber toplama süreçlerine dâhil olmasıdır. Askeri amaçlar için kullanılmaya başlanan drone'lar (Tremayne ve Clark, 2014; Corcoran, 2014, s. 8; Ntalakas, Dimoulas, Kalliris ve Veglis, 2017, s. 188; Chapa, 2013) son y1llarda habercilik pratiklerinde de kendisine yer bulmuştur (Chamberlain, 2017; Chapa, 2013; Tremayne ve Clark, 2014, s. 235; Goldberg, Corcoran ve Picard, 2013, s. 1). Türkçede "düşük seviyede devamlı gelen ses", "erkek arı" gibi anlamları olan drone’un günümüzde "bir kişi tarafından yerden kontrol edilen askeri ve hobi amaçlı kullanılan insansız hava aracı" gibi bir anlamı da mevcuttur ("Drone”, t.y.). Pilotsuz bir şekilde bir kumandayla uzaktan kontrol edilen drone’lar ilk kullanıma başladıklarında Amerika ordusu için tehlikeli bölgelerde uçuşlar yaparak, gövdesinde bulunan kameralarla görüntüler çekmiş ve ordu için bölge hakkında bilgi toplamıştır (Ntalakas, Dimoulas, Kalliris ve Veglis, 2017, s. 188). Gövdesinde bulunan kamera yardımıyla görüntüleri kaydetmesi drone’u ticari ve sivil hayatta da cazip bir hale getirmiştir. Özellikle habercilik alanında drone kullanımı geleneksel araçların yakalayamadığı birçok görüntüyü kaydetme olanağı sağlamaktadır. Doğal afet ve spor müsabakalarında belirli bir yükseklikte uçarak istenilen görüntüler yakalanmaktadır. Ayrıca, doğal afetlerde araçların gidemediği bölgelere uçarak felaketin boyutları hakkında detaylı bilgi ve çarpıcı görüntüleri topluma aktarmaktadır. Bununla birlikte drone'lar, ana akım medyanın topluma sunmadığı alternatif birçok görüntüyü topluma aktarma gücüne sahiptir. Helikopterle çekilen görüntülere nazaran çok daha küçük ve insansız olması, maliyetinin hobi amaçlı kullanılacak kadar düşük olması da drone’lara olan ilgiyi artırmıştır. Bu durumda medya kuruluşları da muhabirlerine drone ehliyeti aldırmış ve drone kullanımına başlamıştır.

$\mathrm{Bu}$ çalışmada, günümüzde bir habercilik pratiğine dönüşen drone’ların Türkiye'deki medya kuruluşlarında kullanımları ve geleceği, drone muhabirleri ile yapılan mülakatlarla ortaya konmaktadır. Çalışmada, Türkiye’de faaliyet gösteren Anadolu Ajansı (AA), Demirören Haber Ajansı (DHA) ve İhlas Haber Ajansı (İHA) muhabirleriyle görüşmeler gerçekleştirilmiştir. Çalışmada üç bölüm bulunmaktadır. İlk bölümde drone ve drone gazeteciliği ile Türkiye’de drone gazeteciliği 
üzerine kuramsal çerçeveye yer verilmiştir. İkinci bölümde muhabirlerle yapılan görüşmeler sonucunda drone gazeteciliğinin Türkiyedeki durumuna ilişkin tespitler ortaya konmaktadır. Son olarak, bulguların değerlendirildiği sonuç ve tartışma bölümü bulunmaktadır.

\section{Drone'lar ve Drone Gazeteciliği}

Amerikan Federal Havacilık Yönetimi (FAA) drone’u, pilotsuz bir uçağın askeri veya eğlence amaçlı uzaktan kumandayla kontrol edilerek uçurulması olarak tanımlamıştır (FAA, 2007, s. 1). Kalsın’a (2016) göre drone, Wi-Fi teknolojisiyle çalışıp uzaktan kumandayla kontrol edilebilen, belirli bir süre havada kalıp çekim yapabilen bir üründür (s. 86).

\section{Drone'ların Tarihsel Gelişimi}

Drone gazeteciliğine değinmeden önce drone’un ortaya çıkış ve gelişim sürecine bakmak gerekir. İnsansız Hava Araçları (Unmanned Aerial Vehicles, UAV) olarak bilinen drone'lar ilk olarak Amerikan İç Savaşı sırasında taraflarca kullanılmıştır. Akabinde Japonya, İkinci Dünya Savaşı’nda bomba taşıyan drone'ları faaliyete geçirmiştir (Garamone, 2002, para. 2-3). Amerika, Vietnam Savaşı döneminde de drone'un askeri faydalarından yararlanmış (Longino, 1994), İsrail Savunma Kuvvetleri 1970 ve 1980 'lerde güvenlik amaçlı drone kullanımına başlamıştır (Bone ve Bolkcom, 2003 , s. 2). Drone’lar günümüze gelindikçe askeri kullanımının dışına çıkarak sivil ve ticari alanlarda da kullanılmaya başlanmıştır. Özellikle gövdesinde bulunan kameralarla yüksek mesafelerden görüntü alınabilmesi toplumda ilgi uyandırmış, maliyetinin karşılanabilir olması da ticari ve hobi amaçlı olarak kullanılmasını kolaylaştırmıştır.

Drone'lar, sivil bir kimlik kazandıktan sonra polis uygulamalarında, zirai işlerde, haritalama ve doğal hayatın gözlenmesinde etkin bir şekilde kullanılmıştır. Drone’un bu alanlara yayılmasıyla birlikte medya kuruluşları da haber üretim süreçlerinde drone'ları kullanmayı denemişlerdir. Aslında, gazetecilik alanında gökyüzünden çekilen görüntülerin yer alması yeni bir durum değildir. Helikopter, kullanılarak gökyüzünden kaydedilen görüntüler 20. yüzyılda habercilik alanında zaten etkindir. Ancak drone’u bu kadar yaygın yapan şey, oldukça düşük maliyetli, küçük ve gazeteciler için güvenli oluşudur. Bu durum medya kuruluşlarını drone kullanmaya iten sebeplerdendir (Goldberg, Corcoran ve Picard, 2013, s. 1). 2011 yilında Japonya'da meydana gelen deprem ve tsunamiyle zarar gören Fukushima Nükleer Santrali’ndeki reaktörde oluşan sızıntı büyük bir endişe yaratmıştır. Sızıntı nedeniyle girilemeyen reaktörde ortaya çıan zararın tespit edilebilmesi için drone’lar kullanılmış, drone’lar vasıtasıyla bilgi toplanmıştır (Corcoran, 2014, s. 33-34). Böylelikle drone'lar, insanlar için tehlikeli durumlarda güvenli bir şekilde kullanılabileceğini kanıtlamışlardır.

Drone’ların gazetecilikalanına girmesiyle bu alanda yeni bir tanım getirilmiştir. Drone Gazeteciliği Laboratuvarı̀nın kurucusu Nebraska Üniversitesi’nden Matt Waite, drone’u "gazetecilikte fotoğraf, video ve veri toplamak için küçük bir insansız hava aracı" olarak tanımlamaktadır (Whitaker, 2016). Avantajları medya kuruluşları tarafından fark edildikçe drone'lar özellikle spor müsabakaları, doğal afetler, protesto ve çatışmalarda yoğun bir şekilde kullanılmaya başlanmıştır (Fitzpatrick, 2014, s. 24; Ntalakas, Dimoulas, Kalliris ve Veglis, 2017, s. 193-194; Carroll, 2015, s. 10). Protesto ve çatışmalarda 
yurttaş gazeteciler olaylara ilişkin görüntüleri kaydederek alternatif yayınlar gerçekleştirmiştir. 2011 yilı sonlarına doğru Occupy Wall Street protestolarında yurttaş gazeteciler drone kullanarak topluma canlı yayın akışını sağlamıştır (Gynnild, 2014, s. 336; Captain, 2012). Ayrıca Polonya, Tayland, Venezuela ve Ukrayna’da yaşanan eylemlerde drone’lar görüntülemeye devam etmiştir. Brezilya, Nijerya ve El Salvador'da yaşanan işçi protestolarında, trafik problemlerinde ve seçim süreçlerinde drone'lar kullanılmıştır. 2014'te Soçi Olimpiyatları'nda kullanılan bir drone, yarışan sporcuları kaydederek spor müsabakalarını da izleyicilere sunmuştur (Kalsın, 2016, s. 87). Drone haberciliği için çeşitli birlikler oluşturulmuş, Nairobidde drone gazetecileri için SkyCam adında bir birlik kurulmuştur (Roug, 2014, s. 28). Drone gazeteciliği için Nebraska Üniversitesi’nde Profesör Matt Waite tarafından bir drone gazeteciliği laboratuvarı da kurmuştur. Burada, drone gazeteciliği için gerekli eğitim ve kurslar verilmekte ve drone haberciliği üzerine araştırmalar yapılmaktadır. Ayrıca, drone gazetecileri için bir birlik oluşturulmuştur. Missouri Üniversitesi bünyesinde 2013 yılında Drone Gazeteciliği Bölümü açılmıştır.

Günden güne artan drone kullanımı büyük medya kuruluşlarını da bu alana yöneltmiştir. Rupert Murdoch'un sahibi olduğu The Daily gazetesi habercilik alanında drone kullanan ilk kuruluşlardan biridir (Gibb, 2013, s. 31). BBC Haber Merkezi 2013 yllından itibaren drone denemelerine başlamıştır (Roug, 2014, s. 28). Amerika'da FAA’in izin verdiği onaylı test alanlarından biri olan Virginia Tech'den onay almak için, Associated Press, Getty Images, Reuters, The New York Times, NBC, Univision gibi kuruluşlar anlaşma yapmışlardır (Çalışkan, 2015). Amerika’nın en büyük medya kuruluşlarından biri olan CNN, en büyük drone haberciliği ağlarından birini kurmuştur (Yüksel, 2015).

Drone'ların birçok alanda kullanımının yaygınlaşması bazı etik ve güvenlik sorunları doğurmuştur. Özellikle Amerika'da güvenlik ve özel hayata müdahale gibi konularda sorunlar yaşandığı için drone’un her alanda ve her birey tarafından kullanılmasının sınırlandırılması gibi birtakım önlemler gündeme gelmiştir. FAA, Amerika'da drone gazetecileri için bazı sınırlandırıcı yasalar getirmiş ve drone kullanımı için medya kuruluşlarını izin ve anlaşmaya tabi tutmuştur. $\mathrm{Bu}$ hususta FAA’den uçuş izni alan ilk medya kuruluşu CNN’dir (Kavaklı, 2018, s. 163).

\section{Türkiye'de Drone Gazeteciliği}

Dünyada gazetecilik alanında drone kullanımı bu denli artış gösterirken Türkiye'deki medya kuruluşları da haber üretim sürecinde drone’lara yönelmiştir. Türk Dil Kurumu (TDK) drone için bazı kelime önerilerini sunmuş ve oylama sonuçlarıyla drone’a karşılık gelen "uçangöz" ifadesinin kullanılmasını tercih etmiştir. Türkiyede habercilikte drone kullanımının öncüleri ise haber ajansları ile TRT olmuştur. Başta AA ve TRT olmak üzere, DHA ve İHA haber üretim sürecinde drone’ları etkin bir şekilde kullanmaktadır. AA’nın drone kullanımında ilk başta drone sayısı 25-30 iken 2018 yılında bu sayıyı iki katına çıkarmayı hedeflemektedir. İHA 25, DHA 3, Reuters İstanbul'da 1, European Pressphoto Agency (EPA) İstanbul'da 1 drone’u habercilik alanında kullanmaya başlamıştır (Şahin, 2018a, s. 185). Türkiye'de drone'la ilk habercilik görüntüsü deneyimini DHA yaşamıştır. Türkiye'de yapılan bir araştırmaya göre, 2016 yılında 8 bin 349 drone ve 11 bin 839 drone kullanıcısı bulunmaktadır (“Drone'lar hayatın", 2017). 
2018 yılı istatistiklerine bakıldığında Kasım ayı itibariyle Sivil Havacılık Genel Müdürlügüne (SHGM) kayıtlı 50 bin hava aracı kullanıcısı bulunmaktadır. Bunların 35 bini pilot olarak uçuş yapmaktadır. 27 bin kayıtlı drone mevcut (SHGM, 2019) ve 10 binin üzerinde uçuş izni başvurusu yapılmıştır (SHGM, 2018). Bu başvurulardan yalnızca 1200 başvuruya izin verilmiştir.

Güvenlik, arama-kurtarma gibi alanlarda kullanılmaya başlanan drone’lar aynı zamanda emlakçılık ve kurbanlık kovalama gibi işlerde de faal olmuştur (“Drone’lar hayatın”, 2017). Drone Türk Grubu'nun kurucusu Mustafa Kaçan, 2017 yılı içinde 25-30 bin arası drone kullanıcısı olduğunu belirtmiştir ("Dronelar artık”, 2017) Siirt'in Şirvan ilçesinde yaşanan maden kazasında işçilerin kurtarılması için drone'lardan yararlanılmıştır. Ayrıca benzer durumlarda kayıp olan kişileri bulmak için termal kameralara takılmış drone'ların operasyonlarda oldukça faydası olmuştur. Denizde belirlenen güvenlik şeridini geçen kişileri drone’lar kaydederek, cankurtaranlara bildirmektedir ("Drone'lar hayatın”, 2017). Oldukça farklı alanlarda kullanan drone'lar habercilik alanına girişi de hızlı olmuştur. 2013 yılında yaşanan Gezi Parkı Eylemleri’nde Taksim Meydanı’nda görüntü yakalamak isteyen bir yurttaş gazetecinin uçurduğu drone polisler tarafindan vurularak düşürülmüştür (Roug, 2014, s. 32).

Türkiye'de drone kullanımının artışı ile birlikte SHGM güvenlik ve özel hayatın gizliliği ilkesince birtakım kurallar getirmiştir. Ağırlığ 1500 gram ve üstü olan cihazlara kayıt yaptırma zorunlu hale gelmiştir. Medya kuruluşlarının da dâhil olduğu, özellikle ticari amaç için kullanılacak drone’ların birtakım belge, ehliyet ve özel uçuş izinlerini almaları gerekmektedir. Ayrıca belirlenen güvenlik bölgeleri ve uçuşa yasak bölgelerde drone uçurulması önlenmiştir. Uçuşun yapılacağı tarihlerde valilik ve mülk sahibinden izin alınması gerekmektedir (SHGM, 2017).

\section{Yöntem}

\section{Çalışmanın Amacı}

Son yıllarda drone'lar askeri amaçlı kullanımının dışına çıkarak haber üretim sürecine dâhil olmuştur. Bu çalışmada, haber üretim sürecine dâhil olan drone’ların Türkiye medyasındaki kullanım durumu, habercilik alanına olumlu ve olumsuz etkileri ile habercilikteki geleceğinin incelenmesi amaçlanmaktadır.

\section{Çalışmanın Önemi}

Günden güne artan teknolojik gelişmelerin habercilik alanına girişi habercilik pratiklerini değiştirmektedir. Drone’un haber üretim sürecine dâhil oluşu ile haber toplamada yaşanan kolaylık ve güvenlik gibi haber üretim sürecindeki değişikliklerin incelenmesi gazetecilik mesleğinin evirileceği yönü belirleme açısından önem taşımaktadır. 


\section{Çalışmanın Örneklemi}

Haber amaçlı kullanılan drone'ların incelendiği bu çalışmada, Türkiye’nin en büyük haber ajansları olan AA, DHA ve İHA’da drone kullanan muhabirlerle yapılandırılmış görüşme yapılmıştır. AA’dan 5, DHA'dan 5 ve İHA'dan 5 muhabirle görüşme gerçekleştirilmiştir. Sözü edilen ajansların seçilme sebebi, bu ajansların Türkiye'de en geniş haber, muhabir ve büro ağına sahip olmasıyla gerçek anlamda bir ulusal ajans olma niteliği taşımalarıdır. Türkiye'de geniş bir ağa sahip olan bu ajansların ülkedeki drone haberciliği için en doğru verileri sunacağı düşünülmektedir.

Çalışmanın sınırlılı̆̆ını ise görüşme yapılması planlanan muhabirlerin sorulara cevap vermedeki isteksizliği ve çalışmaya dâhil olmaktan kaçınmaları oluşturmaktadır. Ajans editörlerinin ricasıyla yapılan çabalar sonucu 4 aylık bir süreçte görüşmeler gerçekleştirilebilmiştir. Ayrıca çalışmada görüşme yapılan muhabirlerin isimleri yer almayacak olup, görüşmecilerden "katılımcı" olarak bahsedilecektir. Katılımcılar alfabetik olarak sıralanarak numaralandırılmıştır.

\section{Çalışmanın Yöntemi}

Drone haberciliğinin Türkiye'deki durumunu resmetmeyi planlayan bu çalışmada muhabirlerle yapılandırılmış görüşme tekniği kullanılmıştır. Yapılandırılmış görüşme tekniğinin seçilmesi, muhabirlerle yapılan görüşmelerde elde edilecek verilerin sistemli bir şekilde analiz edilmesini, uygun temalara ayrılmasını ve karşılaştırmalı bir biçimde yorumlanmasını kolaylaştırmaktadır. Çalışmada AA, DHA ve İHA’nın habercilik sürecinde drone kullanan muhabirlerine drone gazeteciliğinin Türkiye'deki durumu ve geleceğine ilişkin sorular ${ }^{2}$ sorulmuş, verilen cevaplar betimsel analiz yöntemiyle çözümlenerek drone gazeteciliği için sonuç ve tespitlere ulaşılmıştır.

Yapılandırılmış görüşmede, sorulacak sorular ve sorunların sıralaması önceden hazırlanmaktadır. $\mathrm{Bu}$ durum görüşmecinin sorulara ve sırasına uygun hareket etmesini gerekli kılmaktadır. Bu durum, görüşmecinin hareket alanını sınırlandırmakta ve soruların belirlediği bir çerçeve çizmektedir (Karasar, 2013, s. 167).

Nitel araştırma tekniği olan görüşmenin sonucunda elde edilen verilerin analiz edilmesi noktasında kullanılan yöntemlerden biri, betimsel analiz yöntemidir. Çalışmada sorularına göre oluşturulan temalar betimsel analizle yorumlanmakta ve elde edilen veriler anlamlı bir şekilde tasvir edilmektedir. Araştırma bulgularının betimlenmesinin ardından bu betimlemeler neden sonuç ilişkisi içerisinde harmanlanarak genel sonuçlara varılmaktadır. Betimsel analizde, sıra dışı cevapların vurgulanması amacıyla doğrudan alıntılara sıkça yer verilmektedir (Yıldırım ve Şimşek, 2013, s. 158-159).

Betimsel analiz yönteminde öncelikle araştırmanın bir çerçevesi oluşturularak bu çerçeveye göre temalar belirlenmektedir. Çizilen çerçeveye ilişkin veriler toplanarakanlamlı bir bütün oluşturulmakta, akabinde veriler anlamlı bir şekilde tanımlanmakta ve direkt alıntılarla güçlendirilmektedir. Son olarak da bulgular, neden-sonuç ilişkisi içinde yorumlanmaktadır (Yıldırım ve Şimşek, 2013, s. 159). 


\section{Araştırma Bulguları}

\section{Drone Muhabirleri ile Yapılan Yarı Yapılandırılmış Görüşmelerin Betimsel Analizi}

Araştırma kısmında AA, DHA ve İHA'da drone kullanan muhabirlerle yapılan yapılandırılmış görüşmeler sonucunda elde edilen bulgular, betimsel analiz yöntemiyle incelenecektir. Araştırmada seçilen haber ajanslarının Türkiye’de drone haberciliğinin tam manasıyla bir temsiliyetini sağlayacağ düşünülmemektedir. Türkiye’nin en büyük üç haber ajansı olmaları, tüm bölgelere erişim ve faaliyet olanağına sahip olmaları ve daha fazla sayıda drone muhabiri barındırmaları sebebiyle drone haberciliği üzerine farklı perspektif ve görüşlerle Türkiye’deki drone haberciliğinin olabildiğine geniş bir profili çıkarılmaya çalışılacaktır.

Çalışmada yapılan görüşmeler sonucunda elde edilen veriler araştırma soruları kapsamında belirlenen dört temaya göre kategorize edilmiştir. Bu temalar şu şekildedir:

1) Muhabirlerin drone kullanımına bakış açısı

2) Drone’un habercilik alanında kullanımı ve haberciliğe etkileri

3) Habercilikte drone kullanımında yaşanan zorluklar

4) Drone’un habercilik alanında gelecekteki kullanımı

\section{Muhabirlerin Drone Kullanımına Bakış Açısı Temasının Analizi}

“Muhabirlerin Drone Kullanımına Bakış Açısı” teması, görüşülen muhabirlerin drone’u nasıl tanımladıkları ve drone’u kullanma sıklıkları gibi drone hakkındaki genel görüşleri incelemektedir. Haber ajanslarında çalışan drone muhabirlerinin drone geçmişleri ortalama süresi iki yıl olarak karşımıza çıkmaktadır. En eski drone kullanan muhabirler dört yıllık bir geçmişe sahipken, günümüze en yakın tarihli drone kullanmaya başlayan muhabirler bir yıldır operatörlük yapmaktadır. Muhabirler, SHGM'nin yanı sıra üniversitelerde (Ondokuz Mayıs Üniversitesi Havacılık ve Uzay Teknolojileri Uygulama ve Araştırma Merkezi, UZAYTEM) ya da özel havacılık kurumlarında alınan kurslarla drone ehliyeti sahibi olmuşlardır. Amerika ve Güney Amerika'da (Kolombiya, Ekvator, Peru) drone kullanımını karşılaştıran bir çalışmada benzer şekilde ehliyet almanın zorunluluğu ifade edilmektedir (Cruz Silva, 2016, s. 558-559). Amerika’da ise, alınan eğitimler sonrasında zorlayıc1 yazılı bir sınav yapıldığı bilinmektedir (Whitaker, 2016).

Drone kullanan muhabirlerin üye olduğu herhangi bir topluluk bulunmamaktadır. Muhabirler genellikle drone muhabirleri için açılmış sosyal medya gruplarında paylaşımda bulunmakta ve gruplar aracılığı ile iletişim sağlamaktadır. Ayrıca DHA drone muhabirlerinin bir WhatsApp grubu aracılığı ile iletişim kurdukları belirtilmiştir. Yalnızca, Bursa’da yaşayan drone muhabirleri sosyal medya hesaplarından tanışıp Bursa Drone Derneği'ni kurmuşlardır:

Biz Bursa'da sosyal medyada tanışıp yine sosyal medyada oluşturduğumuz Bursa Drone Kulübünü dernekleştirdik. Bursa Drone Derneğini kurduk ve hali hazırda bir karar defterimiz var şükür. (Katılımcı 15) 
Muhabirlerin drone’u nasıl tanımladıkları ile ilgili görüşlerde drone’un şekilsel olarak tanımı yapılmış, ne için ve nasıl kullanıldığına yönelik açıllamalar ifade edilmektedir. Özellikle drone’u uzaktan bir kontrol kumandası, bataryası olan uçan bir kamera olduğu manasında tanımlara işaret edilmektedir. Drone’un bu tanımları dışında muhabirler tarafından dikkat çekici tanımlamalar da ortaya konmaktadır. Bu tanımlamalarda drone’un gerçekten çok faydalı, mucizevi bir icat ya da araç olduğuna yönelik yorumlar dikkat çekmektedir. $\mathrm{Bu}$ yorumlarda drone’un gökyüzünden iyi bir perspektif ve açıla muazzam görüntüler yakaladığı, Mc Krisken’in (2018) de ifade ettiği gibi (s. 139) drone’un insanların gökyüzündeki gözü, kulağı olduğuna yönelik görüşler dikkat çekmektedir:

Drone yalnızca haberciler için değil birçok sektör için inanılmaz bir araç. İnsanların gökyüzündeki gözü, kulağı, eli ayağı gibi, onunla birlikte siz de uçuyorsunuz, onun gördüğü ne varsa sizin de gördüğünüz bir uçan kamera. (Katılımc1 6)

İnsanoğlu tarihte uçma isteğini gökyüzüne olan merakını bir şekilde gidermiştir. Günümüzde de biz içerik üreticileri İnsansız Hava Araçları yani dronelarla bu işi yapıyoruz. Kısacası bana göre drone insanların gökyüzünden görme ihtiyacını gidermesine yardımcı olan bir araç. (Katılımc1 1)

...Ayrıca Drone, fotoğraf veya görüntü çekmek isteyen bir kişinin, en geniş çerçeveden bakabilmesini sağlayan ve sonsuz bir perspektife sahip olmasını sağlayan en değerli gözü ve objektifidir. (Katılımcı 7)

\section{“Drone’un Habercilik Alanında Kullanımı ve Haberciliğe Etkileri” Temasının Analizi}

"Drone'un habercilik alanında kullanımı ve haberciliğe etkisi" teması drone muhabirlerinin drone’un habercilik alanındaki kullanımına ilişkin verdikleri cevapların analiz edilmesini kapsamaktadır. Drone’un habercilik alanındaki kullanım sıklığına ilişkin farklı yanıtlar göze çarpsa da bu yanitlar arasında büyük farklar görünmemektedir. Muhabirlere göre drone’un kullanım sıkılığını etkileyebilecek faktörler bulunmaktadır. Özellikle uçuş yapılacak bölgeden alınması gereken izinler gibi yasal işlemlerin halledilmesi gerektiği için bazen uçuşlar iptal edilebilir. Bu da kullanım miktarını düşürmektedir.

Drone aslında muhabirlerin de sık kullanmak istediği yani kendi adıma öyle bir alet. Ancak drone kullanmanın belli izinleri ve prosedürleri var. Bu izinler alındığı zaman genelde 2 günde bir kez kesin kullanılır. (Katılımcı 10)

Drone’un kullanım sıklığı hakkında bilgi veren muhabirlerse, genellikle drone’u günde iki kez, günde bir kez, haftada birkaç kez ya da iki günde bir kez gibi sıklıkla kullandıklarını dile getirmişlerdir. Verilen cevaplara göre, drone’u kullanım sıklığını etkileyen diğer bir faktör de yaşanılan şehrin büyüklüğü olarak karşımıza çıkmaktadır. Daha sık kullanan muhabirlerin İstanbul ve Ankara’da çalıştı̆̆ görülmektedir.

Drone kullanan muhabirler drone’un birçok haber türünde kullanıldığını, ancak her haberde gerekli olmadığını ve fark yaratmayacağını belirtmişlerdir. Verilen cevaplar dikkate alındığında drone, habercilik alanında en çok "spor müsabakaları, toplumsal olaylar, doğal afetler, trafik 
raporlama, mitingler" (Waite, 2014; Cruz Silva, 2014, s. 2; Tremayne ve Clark, 2014; Shakya, 2017) inşaat çekimleri, gibi durumlarda kullanılmaktadır. Bir haberde drone kullanılmasındaki en temel göstergelerden biri elde edilen görüntünün ya da fotoğrafın klasik bir çekimden çok daha ilgi çekici ve farkındalık oluşturacak boyutta olmasıdır. Drone kullanımının diğer bir ölçütüyse çekim yapılacak yere güvenlik sebebiyle girilemeyecek olmasıdır.

...Örneğin bir ekonomi haberi için yüksek binaların çekimleri drone ile yapılabilir. Buradaki temel kıstas drone’un size bir şey katıp katmayacağı. Örneğin büyük bir fabrika yanıyor ve sizi ana giriş kapısından bile içeri almıyorlarsa drone ile yangının tam üzerine kadar gidip farklı açılardan rahat rahat üstelik güvenliğinizi de tehlikeye sokmadan görüntülerinizi elde edebilirsiniz. (Katılımcı 5)

Katılımcı 1 genellikle açık alanda yapılan spor müsabakaları ve yangın gibi durumlarda kullanılabileceğini, Katılımcı 2 ise denizden görüntü alınmak istendiğinde ve doğal afetler gibi durumlarda iyi görüntüler çekileceğini ifade etmektedir. Katılımcı 3 ise, doğal afetlerin yanı sıra toplumsal olaylarda "genel bir çerçeveden alanın görünüşünün" sağlanabileceğine dikkat çekmektedir. Drone’un ne tür haberlerde kullanılacağına ilişkin bir diğer kıstas da şehrin nitelikleriyle ilgilidir. Antalyada çalışan bir drone muhabiri turizm faaliyetlerinin yoğun olması sebebiyle turistik mekânların çekimlerinin çok sık yapıldığına işaret etmektedir.

Özellikle Antalya gibi turizm kenti olan bir şehirde gazetecilik yaptığımdan dolayı burada çok fazla turizm haberi oluyor ve bu durumda biz muhabirlerin çok sık drone kullanmamızı gerektiriyor. Çünkü şehrin kuşbakışı görünümünü, sahillerini, antik kent ve tiyatrolarını haber yaparken drone ile hem geniş hem kuşbakışı görüntülerle haberi çok daha izlenir ve okunur hale getirmiş oluyorsunuz (Katılımc1 7).

Drone'un habercilik alanında oluşturduğu etkiye bakıldığında, muhabirler drone’un habercilik alanında bir dönüşüm sağladığına inanmaktadır. Bellows'un (2013) ifade ettiği gibi, drone’lar habercilik pratiklerinde bazı değişimlere imza atmaktadır, çünkü geçmişe göre hız kazanan yaşamda ayrıntıların yakalanması da hız gerektirmektedir. Drone da, geçmişte helikopterle yapılan görüntüleme sistemine göre çok daha hızlı ve kullanışlıdır. Ayrıca drone kullanılan haberlerde, kanalların ve haber sitelerinin fotoğraf ve görüntü seçiminde drone çekimlerini tercih ettiği belirtilmektedir. İzleyici ve okuyucuların drone'la üretilen içeriğe daha çok ilgi gösterdiği, beğeni sunduğu ifade edilmektedir (s. 96). Cruz Silva’nın (2014) Ekvator'daki drone muhabirleriyle yaptığı çalışmada, muhabirler net ve kaliteli drone görsellerinin izleyici ve okuyucular tarafından beğeniyle karşılandığını aktarmaktadır (s. 26). Bunların dışında, muhabirler tarafından drone’un bireyin ulaşamayacağı yerlere uçup görüntü kaydedebilmesi, haberle ilgili bilgi ve görsel elde etmede kolaylaştırıcı olduğu ve güvenli bir yol olarak karşımıza çıktığı ifade edilmektedir (Carroll, 2015, s. 9).

...Diğer iller haricinde İstanbul'u ele alacak olursak yol, okul bahçesi ve inşaat çalışmalarında toprak kaymaları oluşmuş ve bunların büyük çoğunluğu medyada drone görüntüleri ile yer almıştır. Drone kullanımı geniş açı görüntü sağladığı gibi, aynı zamanda güvenlik açıssından uzak kaldığınız olay yerine yüksekten yaklaşarak çekim yapabilmenizi sağlamaktadır. ... 
$\mathrm{Bu}$ görüntülerde televizyon ve gazeteler tarafından öncelikli olarak tercih edilmektedir. (Katılımc1 2)

Yalnızca Katılımcı 1 drone’un habercilik pratiklerini değiștirmediğini, habercilik pratiklerine farklılık getirdiğini savunmaktadır:

Her zaman farklı bir bakış açısı ilgi görmüştür. Biz foto muhabiri veya gazeteciler olarak drone dışında klasik anlamda fotoğraf çekiyoruz sadece farklı görebildiğimiz bir aracı kullanarak alışılmamış açılarla içerik üretiyoruz. Ayrıca günümüzün getirdiği yeniliklere sektörümüzün de ayak uydurması açısından önemli olduğunu düşünüyorum. Kısacası drone’u birikimle oluşan gazeteciliğin bir parçası olarak görüyorum.

Drone’ların habercilik alanına sağladığı katkılara bakıldığında, muhabirler genel olarak drone’un çalışma alanlarına farklı yönleriyle olumlu etkilerde bulunduğunu belirtmektedir. Öncelikle ekonomik olarak katkıları incelendiğinde, Katılımcı 7 geleneksel yöntemlerle havadan görüntü alırken bir helikopter kiralanması gibi bir durum söz konusu olduğunu ve bunun maliyet açısından haber kuruluşlarını zor duruma soktuğunu belirtmektedir. Katılımcı 7, drone'ların küçük ve maliyeti çok daha ucuz, taşınabilir olmasının haberlerde kullanılma sıklığını oldukça artırdığını ve maliyetinden dolayı alınamayan görüntülerin çekilmesini, zamandan da tasarruf edilmesini sağladığını ifade etmektedir.

Çok net söylüyorum bu gün bir habercinin kullandığı en yüksek fiyatlı dronenin maliyeti 1 saatlik helikopter kira bedelinin dörtte biri seviyesinde. (Katılımcı 15)

Drone'ların estetik açıdan haberciliğe etkilerine değinildiğinde, muhabirlerin drone'dan söz ederken en çok heyecanlandıkları kısmın çekilen görüntü ya da fotoğrafın estetik yönü olduğu görülmektedir. 2, 8 ve 9 numaralı katılımcılar drone’la yakalanan görüntü ve fotoğrafların geleneksel bir çekimden çok daha geniş, farklı açı ve perspektifle haberciliğe estetik anlamda büyük katkı sunduğuna, gökyüzünden farklı bir gözle görerek hiçbir insanın yapamayacağı bir şeye sahip olunduğuna dikkat çekmektedir. Gagnon, Owen ve Holton’n (2017) muhabirlerle yaptığı görüşmelerde muhabirler, çok daha net, kaliteli ve keskin görselleştirmelerin drone kullanımında etkili olduklarını sarf etmektedir. Drone’un ayrıca estetik açıdan haberciliğe hikâye anlatımı ve sinemasal bir bakış açısı getirdiği düşünülmektedir (s. 5).

Havadan çekim (aerial shot) ve kuşbakışı çekim (bird's-eye shot) gibi sinema tekniklerini de haber kullanımında kullanabilme imkanı ise görüntülü haberlerde sinematik bir tarz getirmiştir. (Katılımcı 3)

Katılımc1 15, drone’un elde ettiği görüntüyü izleyenlerin görüntü ile kendisini özdeşleştirdiğini ve insanların da drone ile birlikte uçuyormuş hissine kapıldıklarını dile getirmektedir:

Estetiğe gelince şırıl şırıl akan bir dere etrafı yemyeşil ağaçlarla bezeli... Üzerinden süzülüp gitmeyi kim istemez ki... İşte bu görsel şöleni drone ile tv karşısındaki izleyicilere yaşatmak mümkün artık. Ya da bir proje düşünün misal Osmangazi Köprüsü, bulutların arasından bir gerdanlık gibi iki yakayı birleştiren köprünün kuş bakışı eşsiz görüntülerini izlemek kimin hoşuna gitmez. 
Drone’un habercilikte kullanımında güvenlik konusu da muhabirlerin değindiği noktalardan biridir. Muhabirler, drone’un güvenlik açısından da iyi bir avantaj sağladığını söylemektedir. Şöyle ki, muhabirlerin birçoğu $(4,5,7,8,9,10,14,15$ numaralı katılımcılar) haberi takip ederken her zaman olayın intikal ettiği yere ulaşamadıklarını ifade etmektedir. Olayın yaşandığı yer bir yangın, bir afet ya da toplumsal çatışmanın mahali olabilmektedir. Böyle bir durumda, haberi yapan muhabirin zarar görmemesi için drone'un hayati bir önemde olduğu vurgulanmaktadır. Drone'un olay yerinde olmadan uzaktan kumandayla kontrol edilerek gerekli görüntü sağlamada önemli bir avantajı beraberinde getirdiği açıklanmaktadır. Gagnon, Owen ve Holton’’n (2017) yürüttükleri bir çalışmada, drone muhabirleri drone'un benzer şekilde muhabirin can güvenliğini tehlikeye sokabilecek durumlarda güvenli bir şekilde görüntü alması sebebiyle tercih edildiğini belirtmektedir (s. 5). Katılımcı 5 de, muhabirlerin spor müsabakalarında güvenlik problemi teşkil etmese de drone’un önemli olduğunu söylemektedir:

Bir spor organizasyonunda bir kameraman ya da foto muhabiri düşünün. Doğal olarak organizasyonun gerçekleştiği alana giremezsiniz. Fakat drone sayesinde bu alana rahatlıkla girip kimsenin oyununa engel olmadan birbirinden güzel görseller elde edebilirsiniz.

Drone'ların habercilik alanında kullanımının habercilik yapan kurum ve muhabir için de önemli sonuçları vardır. Katılımcı 3, drone'la çekilmiş görüntülerin izleyiciler, kanal ve haber sitesi editörleri tarafından daha çok tercih edilmesi sebebiyle daha değerli olduğunu ifade etmektedir. Katılımcı 3’e göre, izleyicilerin beğenisini sunması haberlerin okunma ve izlenme sayısını artıracağı düşüncesi ile editör tercihi olmaktadır (Ntalakas, Dimoulas, Kalliris ve Veglis, 2017, s. 194). Bunun dışında Katılımcı 5, drone görüntülerinin video editörlerine diğer haber kuruluşlarından farklı olması için görsel anlamda bir alternatif sunduğunu ileri sürmektedir. Aynı zamanda drone görüntülerinin fazlaca yer verilmesi drone muhabirlerini daha sık kullanmaya ittiği aktarılmaktadır. Katılımcı 7 ise, kurumun kiraladığı bir helikopterle yapılan görüntüden muhabirin şahsına ait bir drone’a geçişin, haber üretiminde muhabiri daha özgür bir hale getirdiğini açıklamaktadır. Mclyntre (2015), Amerika'daki drone muhabirlerinin kamu yararı konusunda daha özgür davranabildiklerini belirtir (s. 163). Katılımcı 11 ve 15’e göre ise, drone görüntüleri görsel anlamda daha kaliteli, daha ulaşılabilir bir habercilikte rekabeti artırmaktadır. Bu rekabetin ise habercilik kalitesini yükselttiği belirtilmektedir.

Drone’un habercilikte kullanımında olumsuz birtakım görüşler ileri sürülmektedir. Drone muhabirleri (Katılımc1 2, 13) drone'un habercilikte kullanılırken bazı etik problemlerin yaşanabildiğine işaret etmektedir. Drone'lar apartmanların hatta gökdelenlerin bile olduğu yüksekliğe çıkarak haneden görüntü alabilmektedir. Bu tür durumlarda habercilik yapmak amacıyla bireylerin özel yaşamına müdahale edildiği dile getirilmektedir. Özel yaşama müdahale genellikle ünlülerle ilgili magazin haberlerinde görülmektedir. Tremayne ve Clark (2014), Paris Hilton’un yatta bulunduğu sırada magazin muhabirleri tarafından drone’la çekilmiş görüntülerinin etik açıdan bir ihlal olduğunu dile getirmektedir (s. 236).

Drone muhabirlerinden Katılımcı 9, drone'un habercilik alanındaki etik sorunlarından birinin de izinsiz uçuş yapmak olduğunu belirtmektedir. Drone muhabirleri uçuş için SHGM'den izin almak 
zorundadır. İzin alınmadan yapılan çekimlerin etik ve güvenlik açısından sorunlar yarattığına dikkat çekmektedir. Amerika'da yapılan yasal düzenlemelerde drone'lar havaalanına en az 8 kilometre uzaktan uçmak zorundadır (Cruz Silva, 2016, s. 559). Öyle ki Katılımc1 7 bu konu üzerine yaşadığı bir hadiseyi şöyle anlatmaktadır:

Havaalanına yakın bir turistik mekânda hava kararmak üzere olduğundan hızlı bir şekilde çekim yapmamız gerekiyordu. Havaalanına yakın bir bölge olduğu için uçuş yasaktı, sadece istisnai durumlarda yapılabilirdi. Drone’u uçurduk ve gizli, saklı görüntüyü aldık. Havaalanı sebebiyle bir güvenlik ya da mahremiyet sorunu yaşasak çok büyük yaptırımlarla karşı karşıya kalabilirdik.

Katılımcı 13 ise, Trabzon’da iniş sırasında pistten çıkan uçağın drone görüntüsünü çekişini şu şekilde anlatmaktadır:

...Havalimanı uçuşa saat 09:00 kadar kapalı olduğunu öğrendim. Drone mi hazırladım ve gün acarken kaldırıp hem görüntü hem de fotoğraf çektim. Kanallar işte düşen uçağın asılı kaldığı yer diye flaş olarak girdi. Ayrıca çektiğim fotoğraf Dünya çapında o haftaki fotoğraflar arasında birinci oldu. Ayrıca Havalimanı üzerinde izinsiz Drone uçurmaktan 236 TL para cezası yedim. Ama şunu deyim ben Havalimanı uçuşa kapalı diye kaldırdım yoksa kesinlikle kaldırmazdım. Çünkü Allah göstermesin iniş esnasında bir uçak olur ve kazaya sebep verebilirim...

Muhabirler, drone kullanımının diğer bir olumsuz tarafınınsa düşme tehlikesi olduğunu belirtmektedir. Drone belirli bir yükseklikten yere düşebildiği için, geleneksel kameralara göre daha hassas yapısı, pervane ve gövdelerinin bir temas halinde paramparça olma ihtimalinden dolayı sorun teşkil etmektedir. Katılımcı 12, drone'ların en büyük sorununun düşme tehlikesi olduğunu dile getirmektedir. Düştügü zaman tamir edilmesi maliyet gerektirirken, düştüğü yere de zarar verebilmektedir (Culver, 2014, s. 58).

\section{“Drone’un Habercilikte Kullanımında Yaşanan Zorluklar” Temasının Analizi}

Drone kullanımı sırasında yaşanan zorluklara değinen muhabirler ilk olarak doğal engellere vurgu yapmaktadır. Katılımc1 1, 2, 5, ve 9 drone uçuşta olduğu zaman ya da uçuşa geçmeden önce hava şartlarının olumsuz olduğu durumlarda büyük problemler yaşandığını dile getirmektedir. Kötü hava şartları drone’un düşmesine neden olabilmektedir. Ayrıca zorlu hava şartlarının drone ile kullanıcının elindeki kumanda arasındaki bağlantıyı sağlayan sinyallerin zayıflamasına ve hatta kesilmesine neden olableceği belirtilmektedir.

Drone kullanımında yaşanan zorluklardan biri de çekim yapılan yerin drone uçuşu için uygun bir ortam sunamamasıdır. Katılımcı 1, insan yoğunluğunun fazla olduğu bölgelerde yaşanan zorlukların, uçuş sağlığını bozan sinyal kirliliği ile sinyal kesici araçların ve binaların çokluğu gibi teknik sorunlarla olduğunu belirtmektedir.

Muhabirlerin drone kullanırken yaşadıkları zorluklarda en çok vurgu yaptıkları konu ise kolluk kuvvetlerinin ve kısmen vatandaşların drone muhabirlerine karşı olumsuz tavrıdır. Katılımcı 1, 11 
ve 12 SHGM ve Emniyet'ten alınan izinlere ve drone ehliyetini göstermelerine rağmen emniyet ekiplerinin drone çekimlerinde sürekli zorluk çıkardıklarını ifade etmektedir. Kolluk kuvvetlerinin zaman zaman tüm izinler alınmasına rağmen görüntü çekimini yasakladığına işaret edilmektedir.

Haberciliğin her dalında olduğu gibi drone kullanımında da zorluklar bulunmaktadır. Vatandaşların yoğun ilgisi zaman zaman zorluk yaşatsa da asıl sıkıntı emniyet mensuplarının gerekli evraklar gösterilmesine rağmen (bu konuda fazla bilgi sahibi olmadıklarından kaynaklanıyor) drone kullanımı konusunda sıkıntı çıkarabiliyorlar. (Katılımcı 12)

Katılımcı 12 ve 15, drone kullanımında kolluk kuvvetlerinin bu şekilde davranmasına sebep olarak drone'ların teröristler ve kötü niyetli şahıslar tarafından da kullanılıyor olmasını göstermektedir. Drone muhabirleri drone haberciliğinin daha yaygın olmasındaki en büyük engelin kolluk kuvvetlerinin tutumları ve uçuş izni olduklarını belirtmektedir. Ekvator'daki drone haberciliğinin ele alındığ 1 çalışmada muhabirler farklı olarak engelin haber kuruluşu sahiplerinin drone alma konusundaki isteksizliği olduğunu vurgulamaktadır (Cruz Silva, 2014, s. 28).

Drone muhabirlerinin problem yaşadığı bir diğer konu da uçuş izni alabilme sorunudur. Katılımcı 7, 8, 9, 14, 15, çekim yapılacak alanda uçuş için önceden izin alınması gerektiğini ve bu izinlerin alınmasında gerekli prosedürlerin yerine getirilmesine rağmen sürecin oldukça yavaş ilerlediğini ve zorluklar çıktığını ileri sürmektedir. Anlık yaşanan gelişmelerde iznin hızlı alınması gerektiği de ayrı bir sorun olarak karşımıza çıkmaktadır. Tompkins (2017) Amerika'da yapılan bir çalışmada, FAA’nın drone muhabirlerine uçuş izni konusunda benzer şekilde çok geç şekilde cevap verdiği iletmektedir. Ancak bu konuda bir çalışma yürütüldüğünün, anında uçuş izni sağlayan bir sistemin getirileceğinin altını çizmektedir.

Medyanın istediği zaman drone kaldıramaması gerçekten saçma geliyor. Çünkü bir hafta sonra meydana gelecek bir trafik kazasını kimse bilemez. Bu yüzden anlık olaylarda izinsiz kaldırabiliyoruz. Bu bizi rakiplerimizden daha öne geçirdiği için rakiplerimiz bizim izinsiz drone kaldırmamızı şikayet edebiliyor. Nadir olsa da para cezası ile karşı karşıya kalabiliyoruz. (Katılımc1 14)

\section{“Drone’un Habercilik Alanında Gelecekteki Kullanımı” Temasının Analizi}

Drone'ların habercilik alanında kullanımlarının gelecekte nasıl şekilleneceği konusunda görüş belirten muhabirler (Katılımcı 1, 2, 4, 6, 7, 8, 10) genellikle drone’un gelecekte çok daha fazla yaygın olacağını ve hemen her haberde kullanılacağını ifade etmektedir. Bunları söylerken teknolojiye ayak uyduramayan kuruluşların günden güne yok olduğu ileri sürülerek diğer kurumlarla rekabet edebilmenin teknolojiye ayak uydurmaktan geçtiğinin altı çizilmektedir. Çünkü, drone’la çekilen görüntülerin olaylarla ilgili daha gerçekçi, daha etkileyici ve daha estetik görüntüler sağlamasının toplumun beğeni ve ilgisini artıracağ düşünülmektedir.

Mesela elimizdeki drone ile sadece internet ortamından canlı yayın yapılıyorken, biz bunun çözüm yollarını bulup ekrana aktarımını sağladık. Bundan diğer medya şirketlerinin aslında haberi yok diyebilirim. Kısacası sadece drone için değil, hangi teknolojik ilerleme olursa 
olsun, ilk olarak benimseyen kuruluşlar yarışta öne geçiyor. Şimdiden drone’lar pratikliği ve ortaya çıkardığı iş bakımından medya sektörünün vazgeçilmezi haline geliyor. (Katılımcı 14)

Katılımcı 6 ve 11, haber kuruluşlarının gelecekte işe alımlarda drone ehliyeti şartı getirebileceğini ifade etmektedir. Çünkü drone’ların gelecekte habercilik alanında vazgeçilmez bir araç olacağ söylenmektedir (Corcoran, 2014, s. 3). Drone’ların birçok haber türünde ve alanda kullanılacağ iddia edilmektedir. Drone gazeteciliği laboratuvarı kurucusu Waite, drone haberciliğinin geleceğine ilişkin tahminlerinde de drone’ların yeryüzü kaynaklarının kötüye kullanımı, çevresel sorunların görüntülenmesi ve çözülmesinde etkili olacağını ileri sürmektedir (akt. Whitaker, 2016). Gagnon, Owen ve Holton'ın (2017) çalışmasında ise muhabirler, drone'la bir kasırganın haritasının çıkarabileceğini, spektral kameralarla topraktaki nem oranı ve kuraklık gibi birçok durumun tespit edilebileceğini belirtmektedirler (s. 8).

Katılımc1 2, günümüz haberciliğinde görselliğin öneminin arttığını ve bu sebeple haber kuruluşlarının gelecekte drone birimleri kuracağını söylemektedir. Habercilikte drone’un fotoğraf makinesi kadar gerekli olacağına dikkat çekmektedir:

Geçmişte kullanılan, "Fotoğraf makinesiz muhabir olmaz" sözüne, "Drone’suz muhabir olmaz" cümlesi de eklenecektir.

Drone haberciliğinin gelecekteki durumu aktarılırken muhabirler, drone’un yaşayacağı teknik gelişime de değinmektedir. Drone teknolojisindeki ilerlemeyle haberciliğin de etkileneceği dile getirilmektedir. Katılımcı 2 ve 14, drone’ların şu an havada kalabildiği batarya süresi ile ulaşabileceği menzilin artacağını ve uzun soluklu haberler yapılabileceğini öne sürmektedir. Ayrıca menzilin uzamasıyla bürodan ayrılmadan olay yerinden drone çekimi yapılabileceği ihtimalini de gündeme getirmektedirler. Bu durum, drone muhabirlerine ihtiyaç kalmayacağı olasılığını bile düşündürmektedir:

Sanırım gelecekte daha uzun menzilli drone'lar üretilecek ve muhabirler olay yerine gitmeden yaşananları havadan anında görüntüleyebilecekler. Benim en büyük hayalim o günlerin gelmesi fakat o durumda bize de pek gerek kalmayacağını düşünüyorum. (Katılımcı 14)

Drone muhabirleri (Katılımcı 6, 7, 9) drone'ların gelecekte çok daha yaygın kullanılmasının birtakım etik ve güvenlik tartışmaları da beraberinde getirebileceğini dile getirmektedir. Diğer haber kuruluşlarının çekimi yapmadan görüntünün yakalanma hırsı ve daha iyi görüntü sağlama isteğinin etik ve güvenlik kaygısının önüne geçebileceği vurgusu yapılmaktadır.

Haber kuruluşları daha kaliteli ve etkileyici haber görselleri için drone savaşları yapacaklardır. $\mathrm{Bu}$ durum etik sorunları beraberinde getirebilir. Çünkü görüntü alıp yayımlamak için yapılan izinsiz uçuşların özel yaşama müdahale ve güvenlik zafiyeti gibi durumlar yaratması kaçınılmazdır. Bu da drone kullanımı için yeni yasaların geleceğini gösterir. (Katılımcı 6)

Drone’un gelecekte kullanımının artacağına ilişkin genel görüşün yanında Katılımcı 5, kolluk kuvvetlerinin tavrının ve uçuş izni sorunlarının giderilmemesi durumunda drone haberciliğinin gerileyeceğini de belirtmektedir. Katılımcı 15 ise, drone üretiminde dışa bağımlı olmanın maliyetleri 
artırdığını, ileride devletin yerli bir drone projesi ortaya koyacağını ve böylece tekelleşmiş yabancı modellerden bir kurtuluş olacağını aktarmaktadır.

\section{Sonuç}

$\mathrm{Bu}$ çalışmada, teknolojik gelişmelerle birlikte habercilikte kullanılmaya başlanan drone'ların Türkiye'deki yansımaları incelenmiştir. Bu bağlamda haber ajanslarındaki drone muhabirlerinin habercilik alanında drone’a bakış açıları, verdikleri önem, drone'un habercilik alanındaki kullanımları ve alana etkileri ile drone kullanımının gelecekteki durumuna ilişkin görüşler değerlendirilmiştir.

Çalışmanın bulguları çerçevesinde, drone'ların habercilik alanında genellikle olumlu bir değişim yarattığı ve drone kullanımının haberciliğe önemli katkıları olduğu gözlenmektedir. Bu katkılardan en çok vurgulananların gökyüzünden çekilen estetik görsellerin izleyici ve okuyucunun beğenisini kazanması olduğu saptanmıştır. Ayrıca, drone görsellerinin habercilikte fark yaratan içerikler olduğu gözlenmiş ve haber kuruluşlarının öncelikle bu içerikleri yayımladıkları belirlenmiştir. Drone görsellerinin fark yaratması daha kaliteli ve estetik içeriklerin üretilmesini de sağlamaktadır. Geleneksel yöntemlerden helikopter görüntülerine göre zaman ve maliyet açısından oldukça avantaj sağlayan drone'ların muhabir için ulaşılmaz ya da güvenli olmayan yerlere ulaşma imkânı sağladığı da görülmektedir. Bu katkıların yanı sıra nadir de olsa değinilen bazı sorunlar olduğu da göze çarpmaktadır. Söz gelimi, uçuşa yasak alanlarda drone uçurmak ya da özel yaşama müdahale eden görüntüler çekilmesinin güvenliğe yönelik endişeler ve etik sorular doğurduğu ortaya çımaktadır.

Çalışmada ifade edilen görüşler ışığında, Waite'in de ifade ettiği gibi drone’un habercilikte geleceğin en önemli aktörlerinden biri olacağı görülmektedir (akt. Whitaker, 2016). Haber kuruluşlarının drone'lara giderek daha çok önem verdiği, daha fazla sayıda haberde drone kullanıldığı ve drone muhabiri istihdam edildiği karşımıza çıkmıştır. Çağın haberciliği ve gelecekte daha kaliteli ve estetik görsellerin yakalanması, habere konu olan olaya ulaşabilme ve en gerçekçi içeriklerin kaydedilmesi için drone haberciliğinin desteklenmesi gerekmektedir. Kolluk kuvvetleri ve vatandaşlar drone haberciliği konusunda bilgilendirilerek çekimlerin kolay ve daha kısa zamanda yapılması sağlanmalıdır. Ayrıca, etik sorunlar ve güvenlik zafiyeti oluşturan sivil vatandaş ve muhabirlere gerekli cezalar verilerek, kurallar içinde hareket edenler için uçuş izni hızlandırılmalı ve zorluk çıkarılmamalıdır.

Türkiye’de belirli bir yol kat etmiş olan drone haberciliği alanında yapılmış çalışmalar bulunmaktadır (Kavaklı, 2018; Şahin, 2018a). Bu çalışmalar drone kullanımının dünyada ve Türkiye'deki gelişimini inceleyen tarihsel çalışmalardır. Şahin’in (2018b) yaptığı bir diğer çalışmada, drone'la çekilmiş haber görselleri haber değeri bağlamında incelenerek drone’un haber türlerine göre kullanım durumu analiz edilmiştir. Bu çalışma ise, drone haberciliğinin dünyada ve Türkiye’deki gelişimini tarihsel olarak ele almış ve muhabirlerle yapılan görüşmeler neticesinde bulgulara erişerek drone kullanımının sahadaki yansımalarını ortaya koymaya çalışmıştır. Yeni iletişim teknolojileriyle ortaya çıkan drone haberciliğinin giderek etkisini artırması bu alanda yapılacak akademik araştırmaların önemini göstermektedir. İleriki çalışmalarda drone haberciliğinde meydana gelen etik ihlallerin örnek olaylar üzerinden değerlendirilmesi ele alınabilir. Ayrıca, Amerika ve diğer 
Batı ülkelerinde drone’lar için getirilen kısıtlamalar üzerine yapılan çalışmalar Türkiye özelinde de yapilabilir.

\section{Kaynakça}

Bellows, B. (2013). Floating toward a Sky Near You: Unmanned Aircraft Systems and the Implications of the FAA Modernization and Reform Act of 2012. Journal of Air Law and Commerce, 78(3), 586-614.

Bone, E. ve Bolkcom, C. (2003). Unmanned aerial vehicles: Background and issues for Congress. Library of Congress, Washington D.C: Congressional Research Service.

Carroll, R. L. (2015). God's eye news: The use of drones in journalism, a documentary film. Illinois University, Theses and Dissertations. https://ir.library.illinoisstate.edu/cgi/viewcontent.cgi?article=1426\&context=etd adresinden erişilmiştir.

Captain, S. (2012). Livestreaming journalists want to occupy the skies with cheap drones. Wired. 10.10. 2018 tarihinde http://www.wired.com/threatlevel/2012/01/occupy-drones/ adresinden erişilmiştir.

Chapa, L. (2013). Drone journalism begins slow take off. News Media and the Law, 37(2), 9-10.

Chamberlain, P. (2017). Drones and Journalism: How the media is making use of unmanned aerial vehicles. New York: Routledge.

Corcoran, M. (2014). Drone Journalism: Newsgathering applications of unmanned aerial vehicles (UAVs) in covering conflict, civil unrest and disaster. Introductory Paper, Australia: Australian Broadcasting Corporation.

Cruz Silva, J. A. (2014). Is Ecuador prepared to deploy drone journalism? (Yayımlanmamış Yüksek Lisans Tezi). The University of Edinburgh, Edinburgh.

Cruz Silva, J. (2016). Legal and ethical state of drone journalism in Andean Community

Countries. Actas del II Simposio de la Red Internacional de Investigación de Gestión de la Comunicación, 549-565.

Culver, K.B. (2014). From battlefield to newsroom: Ethical implications of drone technology in journalism. Journal of Mass Media Ethics, 29(1), 52-64

Çalışkan, K. (2015). Büyük medya şirketleri Virginia Tech ile drone gazeteciliğine hazırlanıyor. Webrazzi. 12.12.2018 tarihinde https://webrazzi.com/2015/06/17/medya-virginia-tech-drone-gazeteciligi/ adresinden erişilmiştir.

Drone. (t.y.) Cambridge Online Dictionary. 08.06.2018 tarihinde https://dictionary.cambridge.org/dictionary/ english/drone adresinden erişilmiştir.

Dronelar artık hayatın her alanında. (2017, 31 Ağustos) Anadolu Ajansı. 10.06.2018 tarihinde https://www. aa.com.tr/tr/bilim-teknoloji/dronelar-artik-hayatin-her-alaninda-/897590 adresinden erişilmiştir.

Drone'lar hayatın her alanında. (2017, 15 Ocak). Hürriyet. 17.11.2018 tarihinde http://www.hurriyet.com.tr/ gundem/dronelar-hayatin-her-alaninda-40336312 adresinden erişilmiştir.

Federal Aviation Administration (FAA). (2007). Unmanned Aircraft Operations in the National Airspace System. Unmanned Aircraft Program Office, Aircraft Certification Service.

Fitzpatrick, A. C. (2014). Drones for good: Technological innovations, social movements and the state. Journal of International Affairs Editorial Board, 68(1), 19-36.

Gagnon, V. B., Owen, T. ve Holton, A. (2017). Unmanned aerial vehicles and journalistic disruption. Digital Journalism, 5(10), 1226-1239.

Garamone, J. (2002). From U.S. Civil War to Afghanistan: A short history of UAVs. U.S. Department of Defence, American Forces Press Service. Defense.gov. 15.11.2018 tarihinde http://archive.defense.gov/news/ newsarticle. aspx? $\mathrm{id}=44164$ adresinden erişilmiştir. 
Gibb, A. S. (2013). Droning the story (Yayımlanmamış Yüksek Lisans Tezi). The University of British Columbia. Goldberg, D., Corcoran, M. ve Picard, R. (2013). Remotely piloted aircraft systems \& journalism. Reuters Institute for the Study of Journalism. 15.12.2018 tarihinde https://reutersinstitute.politics.ox.ac.uk/ourresearch/remotely-piloted-aircraft-systems-and-journalism adresinden erişilmiştir.

Gynnild, A. (2014). The robot eye witness: Extending visual journalism through drone surveillance. Digital Journalism, 2(3), 334-343.

Kalsın, B. (2016). Geçmişten geleceğe internet gazeteciliği: Türkiye örneği. The Journal of Academic Social Science Studies, 42(3), 75-94.

Karasar, N. (2013). Bilimsel araştırma yöntemi. Ankara: 3 A Araştırma Eğitim Danışmanlık Ltd.

Kavaklı, N. (2018). Drone'ların gazetecilikte kullanımı: Drone haberciliğinin olanakları, zorlukları ve sınırları. Erciyes İletişim Dergisi, 5(3), 160-172.

Longino, D. A. (1994). Role of unmanned aerial vehicles in future armed conflict scenarios. Alabama: Air University Press.

McKrisken, T. (2018). Eyes and ears in the sky - drones, journalism and mass surveillance. J. Lidberg ve D. Muller (Ed.), In the name of security - secrecy, surveillance and journalism içinde (s. 139-154). United Kingdom: Anthem Press.

Mclyntre, K. (2015). How current law might apply to drone journalism. Newspaper Research Journal, 36(2), 158169.

Ntalakas, A., Dimoulas, C., Kalliris, G. ve Veglis, A. (2017). Drone journalism: Generating immersive experiences. Journal of Media Critiques, 3(11), 187-199

Roug, L. (2014). Eye in the sky. Drones are cheap, simple, and potential game changers for newsrooms. Columbia Journalism Review, 28-33.

Sivil Havacılık Genel Müdürlüğü (SGHM). (2017). İnsansız hava aracı sistemleri talimatı (SHT-İHA).

Sivil Havacılık Genel Müdürlüğ̈ (SGHM). (2018). Bireysel görüşme, Erişim Tarihi: 11.15.2018.

Sivil Havacılık Genel Müdürlüğü (SHGM). (2019). SHGM.gov. 6 Mart 2019 tarihinde https://iha.shgm.gov.tr/ public/haberler?ID=1163204 adresinden erişilmiştir.

Shakya, A. (2017). Drones help journalists gain a new perspective. Nyujournalism.org 10.11.2018 tarihinde http://projects.nyujournalism.org/newsliteracy2017/topics/drone-journalism/ adresinden erişilmiştir.

Şahin, M. (2018a). Drone journalism. $5^{\text {th }}$ International Conference on Social Sciences and Education Research, Antalya, Turkey.

Şahin, M. (2018b). Drone gazeteciliğinin haber değerine katkısı ve Türkiye pratiği, İletişim Kuram ve Araştırma Dergisi, (47), 262-272.

Tremayne, M. ve Clark, A. (2014). New perspectives from the sky. Digital Journalism, 2(2), 232-246

Tompkins, A. (2017). The 2018 drone journalism forecast. Poynter.org. 17.9.2018 tarihinde https://www.poynter. org/news/2018-drone-journalism-forecast adresinden erişilmiştir.

Waite, M. (2014). Journalism with flying robots. XRDS: Crossroads, The ACM Magazine for Students, 20(3), 2831.

Whitaker, N. (2016). An interview with Matt Waite about the future of drone journalism. Personel Communication. Medium.com. 08.09.2018 tarihinde https://medium.com/google-news-lab/dronejournalism-an-interview-with-matt-waite-about-the-future-of-drones-in-journalism-7b1811c661aa adresinden erişilmiştir.

Yıldırım, Ş. ve Şimşek, H. (2013). Sosyal bilimlerde nitel araştırma yöntemleri, Ankara: Seçkin Yayıncılık. 
Yüksel, O. (2015). Drone'lar foto-muhabirliği nasıl etkiler? Okanyuksel.com. 12.05.2018 tarihinde http:// okanyuksel.com/2015/03/dronelar-foto-muhabirligi-nasil-etkileyecek/ adresinden erişilmiştir.

Ekler

Ek-1

\section{Çalışma Soruları}

1 - Drone’u nasıl tanımlarsınız? Drone nasıl kullanılır? Drone kullanımı için bir eğitim aldınız mı?

2 - Ne kadar süredir drone kullanıyorsunuz?

3 - Drone muhabirlerinin kurduğu bir birlik ya da topluluk var mıdır? Varsa siz bu toplulukta yer aliyor musunuz?

4 - Drone’u haber amaçlı olarak ne sıklıkla kullanıyorsunuz?

5 - Drone'lar belirli bir habercilik türüne özgü müdür, her habercilik türünde de kullanılabilir mi? Drone’ların kullanıldığı habercilik türleri nelerdir?

6 - Drone kullanımının gazetecilik pratiklerinde bir değişim sağladığını düşünüyor musunuz? Değiştirdiğine inanıyorsanız bunlar nedir?

7 - Drone’un habercilik alanına getirdiği (ekonomik, güvenlik, estetik, etik) olumlu ve olumsuz yanlar nelerdir?

8 - Drone kullanımı habercilikte yaşanan zorluklar veya olumsuzluklar var mıdır? Varsa nelerdir?

9 - Habercilikte drone kullanımının Türkiye'de yeterli derecede yaygın olarak kullanıldığını düşünüyor musunuz? Drone'ların habercilik alanında yaygınlaşması için neler yapılabilir?

10 - Çalıştığınız kurumda drone kullanımına verilen önem nedir? Drone kullanımı için çalışan personel ve drone kullanılarak yapılan haberlerin oranı nedir?

11 - Drone'un gelecekte gazetecilik pratiklerindeki yeri nasıl olacaktır? Güvenlik, yaygınlık, etik, estetik, ekonomik gibi yönlerden nasıl bir durumda olacaktır? 


\section{The Effects of Technological Developments on Journalism Practices: Drone Journalism in Turkey}

Emrah BUDAK ${ }^{*}$

Technological developments have brought some changes and innovations on journalism practices, as in all areas. In the field of journalism, new types of journalism have emerged with the new tools brought by the developing technology. The drone journalism held in Turkey and the world is one of the types of journalism that broughtby the technology. It is observed that the drones, which was used for the military purposes at first (Tremayne and Clark, 2014; Corcoran, 2014, p. 8; Ntalakas, Dimoulas, Kalliris and Veglis, 2017, p. 188; Chapa, 2013; Garamone, 2002; Longino, 1994; Bone and Bolkcom, 2003, p. 2), shifted to the journalism field over time (Chamberlain, 2017; Chapa, 2013; Tremayneve Clark 2014, p. 235; Goldberg, Corcoran and Picard, 2013, p. 1).

Drone that is controlled by man from the ground and is used for military and hobby purposes ("Drone", n.d.; FAA, 2007, p. 1) is becoming increasingly widespread in the field of journalism with images taken from the sky. Drones are convenient tools for taking aesthetic images in dangerous or inaccessible areas for a reporter because they can fly at a certain height and distance (Caroll, 2015, p. 9). Considering such advantages, drones are frequently used in journalism in sports events, natural disasters, protests and conflicts (Waite, 2014; Cruz Silva, 2014, p. 2; Shakya, 2017; Fitzpatrick, 2014, p. 24; Ntalakas, Dimoulas, Kalliris and Veglis, 2017, pp. 193-194; Carroll, 2015, p. 10). Drones has been used for real estate and following-up sacrificial animals in Turkey as well ("Drone'lar hayatın", 2017; “Drone'lar artık", 2017). Drone was alsoused for Wall Street and "Gezi Parkı" movements (Gynnild, 2014, p. 336; Captain, 2012). The use of drone brings about some ethical and safety issues due to its structure and practice, since the images taken by the remote control with drone have been stated as interfering with private life and creating security vulnerabilities with airports and security zones (Tremayne and Clark, 2014, p. 236). Therefore, there are some restrictions of the areas in the countries using drone (Cruz Silva, 2016, p. 559; SHGM, 2017).

In the United States, the major organizations such as Associated Press, Getty Images, Reuters, The New York Times, NBC and Unvision have established a network of drone journalism, (Çalışkan,

Research Assistant, Akdeniz Üniversitesi, İletişim Fakültesi, Antalya, Türkiye, bdkemrah78@gmail.com. Orcid ID: 00000001-6896-7558 
2015) as well as The Daily newspaper (Gibb, 2013, p. 31) and CNN (Yüksel, 2015; Kavakl1, 2018, p. 163; Kalsin, 2016, s. 87). In the UK, the BBC has started using drones since 2013 (Roug, 2014, p. 28). Drones are being actively used in Turkey by TRT and Anadolu Agency (AA), as well as by organizations such as Ihlas News Agency (IHA), Demirören News Agency (DHA) and Reuters (Şahin, 2018, p. 185).

As mentioned above drones are used for journalism in many countries including Turkey. While the introduction of technological developments in the field of journalism in terms of drone journalism brings some transformations, it is important to examine the changes in the news process and the advantages and disadvantages experienced in defining current journalism and determining possible changes in the field of journalism in the future.

This study aims to analyze the use of drone in Turkey's journalistic practice in the context of the positive and negative effects of drone on journalism and the role of drone usage in the future of journalism. In this scope, structured interviews conducted with 15 reporters from Anadolu Agency, Demirören News Agency, Ihlas News Agency which are Turkey's three largest news agency. The data obtained from these interviews were analyzed by descriptive research method. In the data obtained from the analysis in the study, it is seen that the reporters usually have a positive view to the drone, emphasize the ability of the drone to capture images and aesthetic images in difficult conditions. In addition to this, it is mentioned by the reporters that the drone is a smaller and more economical vehicle compared to the large cost flights with hired equipment and helicopters, and they can be used by the licensed reporters which provides freedom to the reporters (Mclyntre, 2015, s. 163). Moreover, they emphasize the visional feature of the drones that the aesthetical images recorded by the drones are welcomed by the reporters and news consumers. Participants also mentioned that it was important for reporting and public opinion to get information and images by flying drone to the region that could be dangerous for reporters and impossible to reach.

There are positive aspects of using drones for both reporters and news consumers. It is pointed out that the images taken with drone are more popular and liked by the users and the findings show that high quality and interesting visuals increase the competition in the reporting and produce more qualified content. However, it is stated that there are security (Culver, 2014, p. 14) and ethical problems when drones fly close to non-flight areas and households. As in the case of studies in the United States (Tompkins, 2017), reporters mostly illustrate situations where the security forces make troubles for using the drone and the necessary permissions for the flight are not taken. However, it is concluded that drone will be used more often in the field of journalism in the future. In the studies carried out in the West (Whitaker, 2016; Gagnon, Owen and Holton, 2017, p. 8), it is explained that the drones can be used for environmental problems and environmental journalism.

Considering the analysis results of the study, it is seen that the drones have many important aspects in terms of journalism. As Bellows stated (2013, p. 96), drones have created a change in journalism and become the eyes of the reporters in the sky (McKrisken, 2018, p. 139). It is observed that these important aspects stand out in areas such as economy, aesthetic, security and journalism profession. In addition to these positive impacts, it can also cause problems in terms of security and 
ethics. In the data obtained, it is stated that drone will be an indispensable tool such as a camera in the future of journalism, technical features of drone will be used in more news and more long-term shots will be able to made. In addition, training of law enforcement officers in order to eliminate the difficulties of reporters in the use of drones and opening a quick and easy way to get permission will be positive for reporters. It is important to make further studies on drone journalism to analyze examine the relationship between communication technologies and journalism. In future studies, it may be suggested to conduct studies to compare drone visuals and traditional visuals. 